heute noch dankbar für die außerordentlich anregenden und vielseitigen Exkursionen, auf denen er es mit großer innerer Anteilnahme verstand, die einzelnen Standortskräfte und ihre Summenwirkung aus dem Bau der Landschaft, dem Klima und der Geschichte des Waldes abzuleiten. Er lehrte seine Hörer nicht nur sehen, sondern weckte in ihnen auch das Interesse für geologische, bodenkundliche, klimatische, historische und wirtschaftliche Fragen, die sich aus der Landschafts- und Standortsbetrachtung ergaben.

Um zu einer räumlichen Gliederung größerer Gebiete (z. B. Mitteldeutschland) und zur Standortsgliederung und -kartierung einzelner Wuchsbezirke (z. B. in Sachsen und Oberschwaben) auf Grund eigener Ideen und Methoden vorzustoßen, hat Krauss Arbeitsgemeinschaften ins Leben gerufen, in denen Geologen, Bodenkundler, Botaniker, Historiker und Forstwissenschaftler tätig waren. Für diese überragenden Leistungen in vorbildlichen Arbeits-Teams wurde ihm im Jahre 1955 der Dr. forest. von der Forstlichen Fakultät der Technischen Hochschule Dresden ehrenhalber verliehen.

Wie Krauss das Ergebnis seiner regionalen Standortserkundungen nutzbar zu machen wußte, zeigt z. B. die mit zahlreichen sprechenden Bildern der Bodendurchwurzelung und mit Farbaufnahmen von Bodenprofilen ausgestattete umfangreiche Gemeinschaftsarbeit „Standortsgemäße Durchführung der Abkehr von der Fichtenwirtschaft im nordwestsächsischen Niederland“ (Thar. Forstl. Jahrb. Bd. 90, 1939). Sie wird noch heute von forstlichen Praktikern Mitteldeutschlands als ,forstliche Bibel“ bezeichnet.

Auch für die systematische Bodenkunde haben diese und frühere Untersuchungen bedeutsame Erkenntnisse geliefert, vor allem durch die erstmalige Beschreibung und Deutung der "gleyartigen Böden", die wir heute als Pseudogley bezeichnen. Ihr gesetzmäßiges, von Muttergestein, Relief und Klima abhängiges Vorkommen, ihre Dynamik, vor allem ihr besonderer Wasserhaushalt mit dem ausgeprägten Wechsel zwischen Austrocknung und Vernässung und ihre Entartung unter Fichtenreinbeständen hat Krauss mit eindringlicher Klarheit aufgezeigt.

Krauss hat früh erkannt, daß die von der systematischen Bodenkunde aufgestellten Typen bei weitem nicht zu einer genaueren Charakterisierung des kleinräumigen Wechsels der Bodenverhältnisse ausreichen, daß man vielmehr zu weit differenzierteren Einheiten vorstoßen müsse, die er Bodenformen nannte bzw. Standortsformen, wenn nicht die Böden, sondern die Wirkungseinheit Boden-Klima-Lage, also der Standort ins Auge gefaßt wird. Von größter Bedeutung für die Standortskartierung und damit für die gesamte forstliche Planung wurde der von ihm geprägte Begriff "forstliche Standortseinheit", in dem diejenigen Standortsformen eines Wuchsbezirks zusammengefaßt sind, die sich durch gleiche waldbauliche Möglichkeiten und Schwierigkeiten auszeichnen.

Alle von Krauss regional durchgeführten Untersuchungen über den Wasserhaushalt, die Bodendurchwurzelung, die Humusauflage und den Mineralstoffgehalt von Blättern und Nadeln basieren auf solchen Standortseinheiten. Damit wurde Krauss in Mittel- und Süddeutschland ebenso wie W. WiтTісH in Norddeutschland richtungweisend für die forstliche Boden- und Bestandesuntersuchung. Sie kann nicht in genügendem Maße fruchtbar werden, wenn sie nicht auf dem zunächst klar erschauten Mosaik der Standortseinheiten aufbaut.

Wir wünschen dem erfolgreichen Forscher und Lehrer, der am Geschick seiner Schüler und Mitarbeiter stets mit warmem Herzen Anteil nahm, daß ihm noch viele Jahre voll Gesundheit und Lebensfreude beschieden sein mögen.

W. LAATSCH

\title{
Verleihung des Justus-von-Liebig-Preises an Prof. Dr. Dr. h. c. W. Wittich
}

Der diesjährige Justus-von-Liebig-Preis ist auf Beschluß des Preiskuratoriums dem Ordinarius für Bodenkunde an der Forstlichen Fakultät der Universität Göttingen, Professor Dr. Dr. h. c. WALTER WitTich verliehen worden. 